useful information essential for the safe and effective placement of the catheter.

- Except in emergencies, catheterization should be performed with full aseptic technique to include handwashing, sterile gloves, masks, hats, gowns, drapes and proper use of a suitable skin antiseptic.

- Catheters placed in less than sterile fashion should be replaced as soon as medically feasible.

As the use of central venous catheters has increased in recent years, so has the prevalence of their associated complications. By following these recommendations, the incidence of these complications and resulting sequelae should be substantially reduced. Users and institutions should review and monitor this clinical activity to assure that the process and outcomes are consistent with high quality patient safety standards.

\section{The Name Game With Pseudomonas}

There appear to be two major changes recently in the life of Pseudomonas maltophilia. First, this low pathogenicity "water bug" is becoming a more frequent colonizer (and perhaps pathogen) in many hospitals. Reasons for this increase (such as greater use of new cephalosporins, carbapenem-eating enzymes produced by this species or widely distributed contaminated common sources) are not clear. Second, the genus designation for $P$ maltophilia has been changed to Xanthomanas.

In our institution we have cultured these strains from tap water and have assumed that occasional breaks in aseptic technique lead to colonization and that use of newer antibiotics selects out Xanthomonas. The next Centers for Disease Control (CDC) National Nosocomial Infection Study update should help determine whether or not sporadi-

\title{
Membership Application Inquiry:
}

Mail to: Secretary

Society of Hospital

Epidemiologists of America

c/o Slack, Incorporated

6900 Grove Road

Thorofare, NJ 08086

1 NAME

CURRENT POSITION:

ADDRESS:

ZIP

Doctoral Degree _ $\mathrm{MD} \_\mathrm{PhD}$

Date and University:

Specify work in hospital epidemiology and related fields:

Dates in this position:

1 Related work in the field:

!

Check type of membership application:

1 - Active Membership

(Calendar year dues \$75)

_. Associate Membership

(Calendar year dues $(\$ 35)$

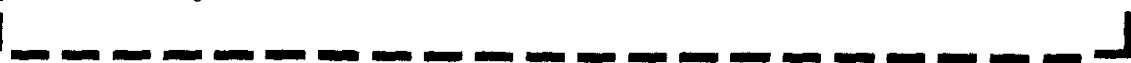

cally reported increases in Xanthomonas represent a true national trend.

\section{Quality Connection}

We have been impressed by the recent series of articles in Infection Control and Hospital Epidemiology edited by Hierholzer and Credé on Quality Assurance. Although many hospital epidemiologists no doubt have hoped that "QA" would go away quietly, it appears that it is here to stay. Moreover, if hospital epidemiology can mate successfully with quality assurance, the offspring hopefully will be greater hospital quality. Decubitus ulcers are a prime example of a problem area where the mating could yield great benefits. If epidemiologic techniques and control measures used successfully over the past four decades in hospital epidemiology can be brought to bear on this problem, perhaps we can prevent the decubiti and learn how to intervene at an earlier step in the development of nosocomial infections.

Brief items of interest for the SHEA Neusletter may be sent to Robert A. Weinstein, $M D$, Shea Neusletter Editor, Dizision of Infectious Diseases, Michael Reese Hospital, Lake Shore Drive at 31st St., Chirago, IL 60616. Copy must be typed, doublespaced and may not exceed five pages. 